\title{
Antihypertensive treatment using an angiotensin receptor blocker and a thiazide diuretic improves patients' quality of life: The Saga Challenge Antihypertensive Study (S-CATS)
}

\author{
Aoi Kamura ${ }^{1}$, Teruo Inoue ${ }^{2}$, Shigetaka Kuroki ${ }^{3}$, Shiro Ishida $^{3}$, Kenichirou Iimori ${ }^{3}$, Toru Kato ${ }^{4}$, \\ Hirofumi Naitoh ${ }^{3}$, Satoshi Tamesue ${ }^{3}$, Hideo Ikeda ${ }^{3}$ and Koichi Node ${ }^{1}$
}

The aim of the Saga Challenge Antihypertensive Study (S-CATS), a single-arm, prospective and multi-center trial, was to evaluate the effectiveness of combined antihypertensive treatment with losartan and hydrochlorothiazide (HCTZ). Enrolled in the study were a total of 161 patients with hypertension, who in spite of treatment with an angiotensin receptor blocker (ARB) alone or an ARB and calcium channel blocker (CCB), had not been able to reach blood pressure control goals set by the Japanese Society of Hypertension Guidelines (JSH 2004). The ARBs were replaced with a combination pill containing losartan $(50 \mathrm{mg})$ and HCTZ $(12.5 \mathrm{mg})$, and this treatment was continued for 3 months. This change in therapy resulted in significant decreases in systolic (158 \pm 14 to $137 \pm 15 \mathrm{~mm} \mathrm{Hg}, P<0.001)$ and diastolic $(85 \pm 11$ to $76 \pm 10 \mathrm{~mm} \mathrm{Hg}, P<0.001)$ blood pressure and heart rate ( $73 \pm 3$ to $72 \pm 3$ ) during the study. The patients' quality of life (QOL) score, the EuroQol 5 dimensions (EQ-5D) and the visual analog scale (VAS) $(n=96 ; 70.0(68.8-80.0)$ to 80.0 (70.0-90.0), $P<0.01)$ all improved significantly. Another QOL score, the hypertension symptom score (HSS), which we originally developed for the S-CATS trial, decreased significantly ( $n=93 ; 4.0(1.0-9.0)$ to $2.0(1.0-8.0), P<0.05)$. The Pittsburgh sleep quality index (PSQI), which is a psychometric assessment of subjective sleep quality, also decreased significantly $(n=45 ; 4.0(2.0-7.0)$ to $3.0(2.0-5.0), P<0.05)$. There was a significant correlation between a change in HSS (baseline value -3-months value) and a decrease in systolic blood pressure ( $n=93 ; R=0.241, P<0.05$ ). These results suggest that an anti-hypertensive treatment combined with an ARB and a thiazide diuretic may improve patients' QOL, including sleep quality.

Hypertension Research (2011) 34, 1288-1294; doi:10.1038/hr.2011.126; published online 4 August 2011

Keywords: angiotensin receptor blocker; combination pill; quality of life; thiazide

\section{INTRODUCTION}

Hypertension is a prevalent and often asymptomatic chronic disease. The goal of antihypertensive treatment is to prevent associated complications and improve cardiovascular morbidity and mortality. To achieve these therapeutic goals, the most important issue is the blood pressure-lowering effect of a therapy. In addition, antihypertensive drugs, such as angiotensin-converting enzyme inhibitors (ACEIs) and angiotensin receptor blockers (ARBs), have been shown to have protective pleiotropic effects in several organs, which may improve patient prognosis. ${ }^{1,2}$ Despite effective medical therapy and evidence-based treatment guidelines for managing high blood pressure, uncontrolled hypertension remains common. ${ }^{3,4}$ Low compliance with antihypertensive medication has been proposed as an important barrier to achieve hypertension control. To maintain treatment compliance or medication adherence, it is essential that patients experience an improvement in their quality of life (QOL) as a consequence of antihypertensive therapy. ${ }^{5,6}$ However, there have been only a few studies that have specifically focused on patients' QOL during antihypertensive therapy.

The Saga Challenge Antihypertensive Study (S-CATS) is a singlearm, prospective and multi-center trial to evaluate the effectiveness of antihypertensive treatment with a combination pill containing losartan and hydrochlorothiazide (HCTZ). In this trial, we specifically focused on the effect of the losartan/HCTZ treatment on the patients' QOL.

\section{METHODS}

Study design

Local physicians and general practitioners at 12 hospitals and 30 clinics in Saga Prefecture, Japan participated in the S-CATS trial. Outpatients with hyperten-

${ }^{1}$ Department of Cardiovascular Medicine, Saga University, Saga, Japan; ${ }^{2}$ Department of Cardiovascular Medicine, Dokkyo Medical University, Mibu, Japan; ${ }^{3}$ Saga Medical Association, Saga, Japan and ${ }^{4}$ Department of Cardiovascular Medicine, Shionoya Hospital, International University of Health and Welfare, Yaita, Japan 
sion were enrolled in this trial if, in spite of treatment with either an angiotensin receptor blocker (ARB) alone or combined therapy with an ARB and calcium channel blocker (CCB), their blood pressure control had not reached the goals set by the Japanese Society of Hypertension Guidelines (JSH 2004). Exclusion criteria included serious cardiac, cerebrovascular, hepatic or renal complications. Exclusion criteria did not include serum levels of $\mathrm{K}$ and creatinine. This study was approved by the ethical review board at Saga University Hospital.

In the treatment regimes of all the recruited patients, the ARBs were replaced with a losartan $(50 \mathrm{mg}) / \mathrm{HCTZ}(12.5 \mathrm{mg})$ combination pill. This treatment was continued for an additional 3 months using the targets included in the 2004 JSH guidelines as the therapeutic goal.

\section{Measurement of blood pressure}

Measurements of blood pressure and heart rate were recorded in duplicate at each clinic visit and $24 \pm 4 \mathrm{~h}$ after the previous administration of the study medication. The recordings were obtained after the patients had rested in a seated position for $5 \mathrm{~min}$, at an interval of at least $1 \mathrm{~min}$. At each visit, which occurred in the morning, office blood pressures were measured to the nearest $2 \mathrm{~mm} \mathrm{Hg}$ in the same arm, using a mercury sphygmomanometer and an appropriately sized cuff. Home blood pressure measurement was recommended for participants using the upper-arm cuff device. Morning home blood pressure was measured twice with the subject with $3 \mathrm{~min}$ rest intervals: within $1 \mathrm{~h}$ after waking, after 1-2 min of rest following micturation, and before taking any antihypertensive drugs or eating breakfast. Just before going to bed, and again after 1-2 min of rest in a sitting position, evening home blood pressure was measured. The measurements of the home blood pressures were averaged over 7 days just before the hospital visit.

\section{Assessment of quality of life}

In the S-CATS trial, we specifically focused on the patients' QOL, using the EuroQol 5 dimensions (EQ-5D) score, the EuroQol visual analog scale (EQVAS), the hypertension symptom score (HSS) and the Pittsburgh sleep quality index (PSQI). The EQ-5D is a generic instrument for measuring health-related QOL, which has been developed and validated in a number of European countries. ${ }^{7,8}$ The EQ-5D evaluates five dimensions of health status: mobility, self-care, usual activities, pain/discomfort and anxiety/depression. Each dimension has three levels of assessment that include 'no problems', 'some problems' or 'severe problems'. This instrument yields 243 potential combinations of health states across the five dimensions. Dolan et al. ${ }^{9}$ measured 42 of these

\begin{tabular}{|cl|}
\hline Symptoms \\
1 & Headache or heaviness of head \\
2 & Vertigo or tinnitus \\
3 & Palpitation \\
4 & Shortness of breath \\
5 & Chest pain \\
6 & Dizziness \\
7 & Edema \\
8 & Loss of concentration \\
9 & Polyuria \\
10 & Neck or shoulder stiffness \\
\hline Frequency \\
None, 0; Occasionally, 1; Sometimes, 2; Often, 3; Always, 4 \\
\hline
\end{tabular}

Figure 1 Calculation method of the hypertension symptom score (HSS). The HSS is a method for estimating patients' QOL, which we originally developed for the S-CATS trial. Each of the 10 listed hypertension-related symptoms was rated $0-4$, for a five-grade scoring system. The HSS was calculated as the sum of each score for the 10 symptoms. Lower scores indicate better health, with a score of 40 being the worst and 0 being the best.
Table 1 Changes in blood chemistry findings during the 3-month observation period

\begin{tabular}{|c|c|c|c|c|}
\hline & $\mathrm{n}$ & Baseline & 3 months & Value \\
\hline AST $\left(\mathrm{UI}^{-1}\right)$ & 126 & $27 \pm 13$ & $27 \pm 11$ & NS \\
\hline ALT $\left(U I^{-1}\right)$ & 126 & $23 \pm 14$ & $23 \pm 14$ & NS \\
\hline BUN $\left(\mathrm{mg} \mathrm{dl}^{-1}\right)$ & 125 & $16.7 \pm 4.1$ & $18.7 \pm 5.1$ & $<0.001$ \\
\hline Uric Acid $\left(\mathrm{mgdl}^{-1}\right)$ & 121 & $5.2 \pm 1.4$ & $5.5 \pm 1.4$ & $<0.01$ \\
\hline Creatinine $\left(\mathrm{mg} \mathrm{dl}^{-1}\right)$ & 124 & $0.77 \pm 0.21$ & $0.81 \pm 0.24$ & $<0.001$ \\
\hline EGFR $\left(\mathrm{ml} \mathrm{min}^{-1} 1.73 \mathrm{~m}^{-2}\right)$ & 96 & $70.9 \pm 19.3$ & $66.7 \pm 17.5$ & $<0.001$ \\
\hline$\geqslant 50$ & 77 & $76.9 \pm 12.8$ & $71.7 \pm 12.2$ & $<0.001$ \\
\hline$<50$ & 19 & $46.7 \pm 8.6$ & $46.4 \pm 10.7$ & NS \\
\hline $\mathrm{Na}\left(\mathrm{mEq} \mathrm{I}^{-1}\right)$ & 121 & $141 \pm 3$ & $140 \pm 5$ & NS \\
\hline $\mathrm{Cl}\left(\mathrm{mEq} \mathrm{I}^{-1}\right)$ & 120 & $104 \pm 3$ & $103 \pm 3$ & $<0.001$ \\
\hline $\mathrm{K}\left(\mathrm{mEq} \mathrm{I}^{-1}\right)$ & 120 & $4.2 \pm 0.4$ & $4.1 \pm 0.4$ & $<0.01$ \\
\hline LDL-C $\left(\mathrm{mg} \mathrm{dl}^{-1}\right)$ & 96 & $116 \pm 30$ & $113 \pm 32$ & NS \\
\hline $\mathrm{HDL}-\mathrm{C}\left(\mathrm{mg} \mathrm{dl}^{-1}\right)$ & 118 & $57 \pm 13$ & $56 \pm 15$ & NS \\
\hline Triglyceride $\left(\mathrm{mg} \mathrm{dl}^{-1}\right)$ & 124 & $130 \pm 79$ & $128 \pm 61$ & NS \\
\hline Fasting Blood Glucose $\left(\mathrm{mg} \mathrm{dl}^{-1}\right)$ & 120 & $112 \pm 45$ & $111 \pm 34$ & NS \\
\hline $\mathrm{HbA1c}(\%)$ & 45 & $6.1 \pm 1.0$ & $6.2 \pm 1.0$ & NS \\
\hline
\end{tabular}

Abbreviations: AST, aspartate aminotransferase; ALT, alanine aminotransferase; BUN, blood urea nitrogen; $\mathrm{Cl}$, chloride; eGFR, estimated glomerular filtration rate; $\mathrm{HDL}-\mathrm{C}$, high-density lipoprotein cholesterol; HbA1c, hemoglobin Alc; K, potassium; LDL-C, low-density lipoprotein cholesterol; $\mathrm{Na}$, sodium.

\section{Table 2 Background of patients}

\begin{tabular}{lc}
\hline Number of patients & 183 \\
Age & $70 \pm 12 \mathrm{y} / 0$ \\
Gender & \\
Male & \\
Female & $45 \%$ \\
BMI & $55 \%$ \\
Abdominal circumference & $24 \pm 5 \mathrm{~kg} \mathrm{~m}^{-2}$ \\
Smoking & $85 \pm 17 \mathrm{~cm}$ \\
$\quad$ Yes & \\
Previously & \\
Never & $12 \%$ \\
Alcohol & $16 \%$ \\
Daily & $72 \%$ \\
Socially & \\
Never & \\
Complication & $20 \%$ \\
Diabetes mellitus & $21 \%$ \\
Hyperlipidemia & $59 \%$ \\
Hyper uric acid & \\
Kidney disorder & \\
Pre-medication & \\
ARB only & \\
Combination of ARB and CCB & $25 \%$ \\
\end{tabular}

Before switching over ARB (mean capacity)

Losartan

$19 \%(52 \mathrm{mg})$

Candesartan

$33 \%(8.5 \mathrm{mg})$

Valsartan

$22 \%(81 \mathrm{mg})$

Telmisartan

$15 \%$ (39 mg)

Olmesartan

$11 \%$ (21 mg) 
health states in a representative sample of the United Kingdom's general population, using the time trade-off (TTO) method. ${ }^{10}$ Based on these evaluations, utility scores can be deduced using an additive function. Utility scores may vary between -0.59 (worst health) and 1.00 (perfect health). In addition to the five dimensions, the EuroQol consists of an EQ-VAS ranging from 0 (worst imaginable health state) to 100 (best imaginable health state). ${ }^{11}$ The HSS is a method of estimating patients' QOL, which we originally developed for the S-CATS trial. This score is calculated as the sum of scores (grades 1-5) of 10 hypertension-related symptoms (Figure 1).

The PSQI is a self-administered questionnaire to assess subjective sleep quality during the previous month. ${ }^{12}$ The self-rated items of the PSQI generate seven component scores (range of subscale scores, $0-3$ ) on sleep quality, sleep latency, sleep duration, habitual sleep efficiency, sleep disturbance, use of sleeping medications and daytime dysfunction. The sum of these seven component scores yields one global score of subjective sleep quality (range of scores, $0-21$ ), with higher scores representing poorer subjective sleep quality. The psychometric properties of the PSQI have been confirmed in previous studies. ${ }^{12,13}$

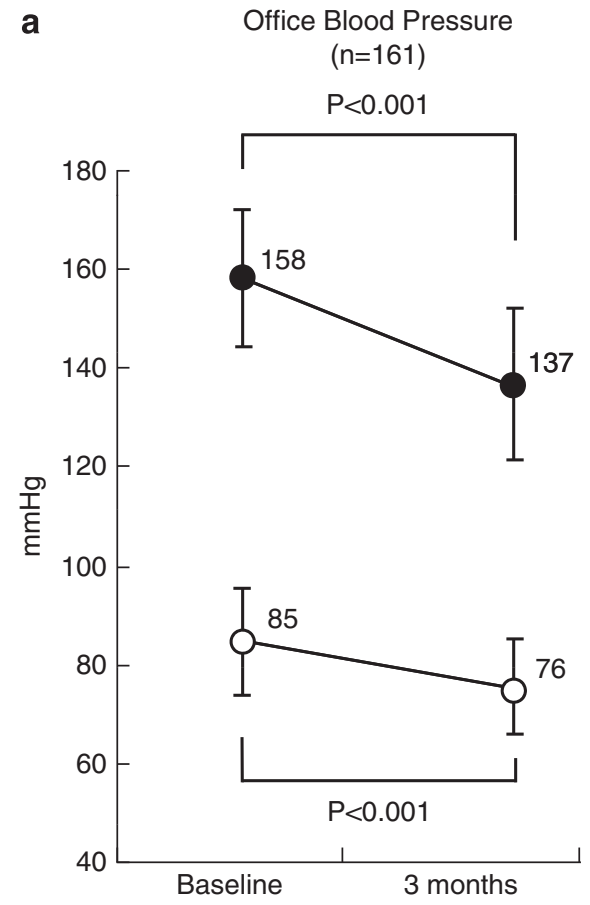

\section{Data analysis}

The data were collected before (baseline) and 3 months after the replacement of ARBs with the losartan/HCTZ combination pill therapy. The values were expressed as mean \pm s.d. for parametric data and as median value and interquartile range for non-parametric data. The statistical analyses were performed using the paired $t$-test for parametric data and the Wilcoxon rank-sum test for non-parametric data. The correlation between the two variables was examined using the Spearman rank correlation coefficient. A $P$ value $<0.05$ was considered to be statistically significant.

\section{RESULTS}

We analyzed the data from 161 patients ( 72 men and 89 women, aged $70 \pm 11$ yrs) who were followed during the 3-month observation period. The characteristics of these patients are summarized in Table 1. There were no major adverse effects in this study. The baseline antihypertensive medications that the patients had been taking before

b
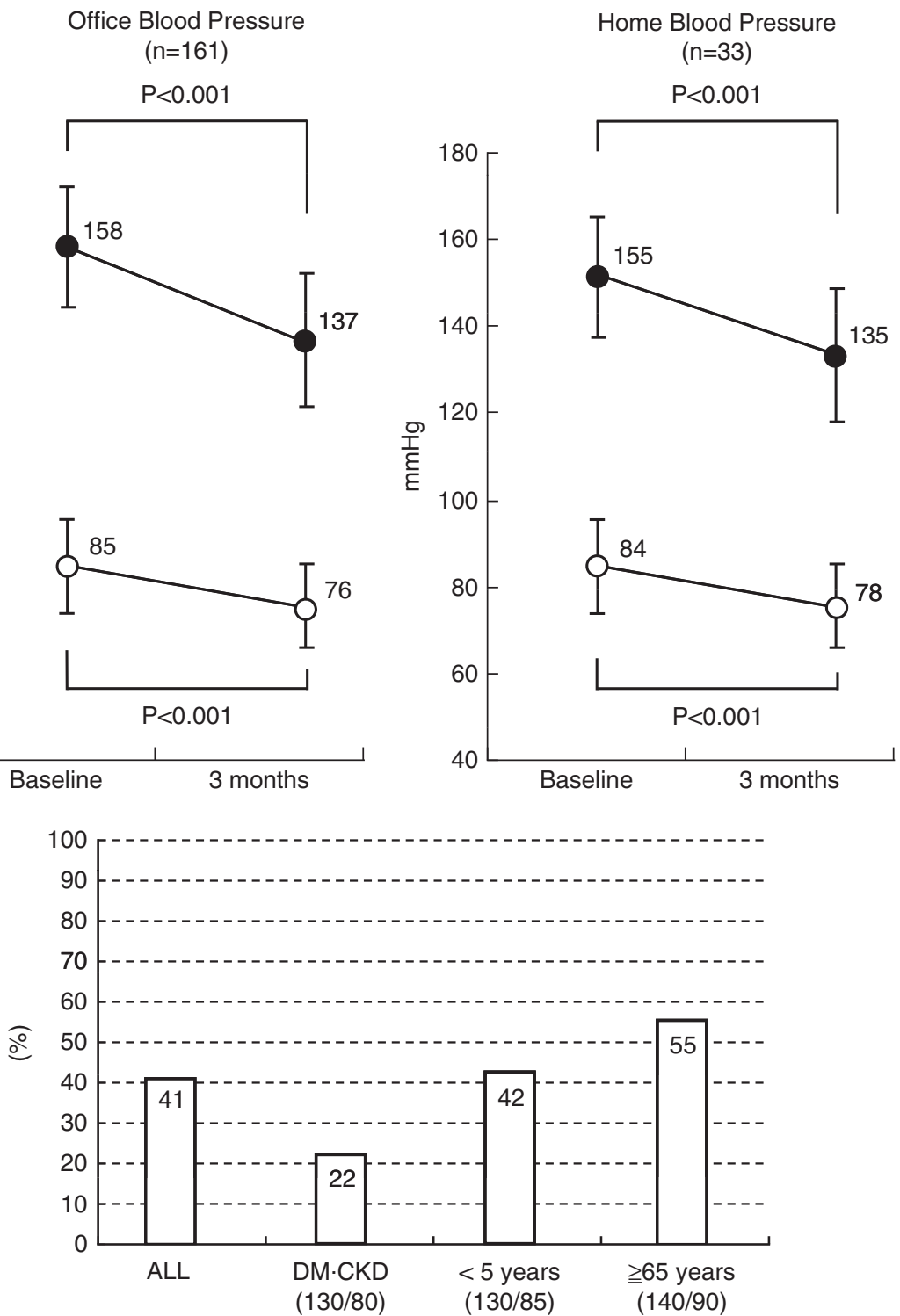

Figure 2 (a) Changes in blood pressure during the 3-month observation period after the replacement of ARBs with the losartan (50 mg)/HCTZ (12.5 mg) combination pill. After 3 months of treatment, the office blood pressures of all 161 patients decreased significantly (left). Home blood pressures also decreased significantly in 33 patients for whom the data were obtained both at baseline and 3 months after treatment with the combination pill (right). - indicates systolic blood pressure, $\bigcirc$ indicates diastolic blood pressure (b) The guideline achievement rate shows the responders' blood pressure-lowering characteristics compared with those of the non-responders after changing the medication. CKD, chronic kidney disease; DM, diabetes mellitus. 
the medication exchange were ARBs alone in 72 patients (45\%) and ARBs with CCBs in 89 patients (55\%). The baseline ARBs were losartan in 31 patients (19\%), candesartan in $53(33 \%)$, valsartan in $35(22 \%)$, telmisartan in $24(15 \%)$ and olmesartan in $18(11 \%)$ (Table 2). During the 3-month observation period, office blood pressure decreased significantly (systolic $158 \pm 14$ to $137 \pm 15 \mathrm{~mm} \mathrm{Hg}$, $P<0.001$; diastolic $85 \pm 11$ to $76 \pm 10 \mathrm{~mm} \mathrm{Hg}, P<0.001$ ) (Figure $2 \mathrm{a}$, left), and heart rate did not change significantly ( $73 \pm 3$ to $72 \pm 3$ ). Home blood pressure also decreased significantly (systolic $155 \pm 21$ to $135 \pm 15 \mathrm{~mm} \mathrm{Hg}, \quad P<0.001$; diastolic $84 \pm 13$ to $78 \pm 11 \mathrm{~mm} \mathrm{Hg}$, $P<0.001$ ) (Figure $2 \mathrm{a}$, right). As the result of adhering to the guidelines of the Japanese Society of Hypertension, there were difficulties in using the drug combination to treat the patients with complications of diabetic mellitus and chronic kidney disease (Figure 2b). The blood pressure-lowering effect was similar between the patients taking ARBs alone and those taking ARBs with CCBs as the baseline medications (Figure 3). In addition, the blood pressure-lowering effect was independent of the differences in baseline ARBs (Figure 4).

Changes in blood biochemistry profiles are shown in Table 1. Significant increases in serum levels of blood urea nitrogen $\left(16.7 \pm 4.1\right.$ to $\left.18.7 \pm 5.1 \mathrm{mg} \mathrm{dl}^{-1}, P<0.001\right)$, uric acid $(5.2 \pm 1.4$ to $\left.5.5 \pm 1.4 \mathrm{mg} \mathrm{dl}^{-1}, \quad P<0.01\right) \quad$ and creatinine $\quad(0.77 \pm 0.22$ to
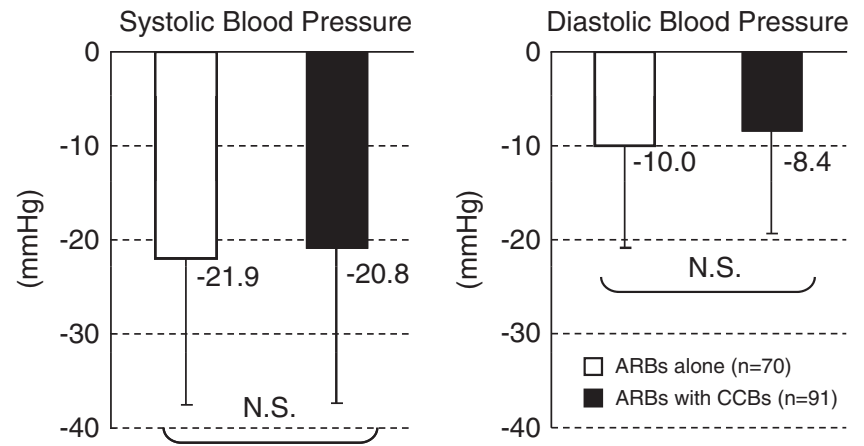

Figure 3 Comparison of the blood pressure-lowering effects between the patients taking ARBs alone and those taking ARBs with CCBs as the baseline medications. The effects were similar between two groups.

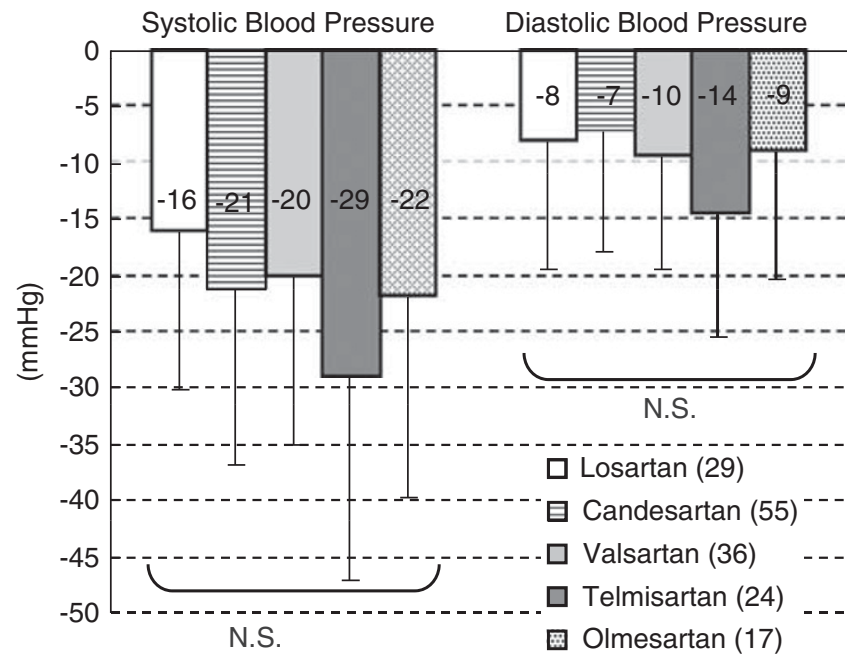

Figure 4 Comparison of blood pressure-lowering effects among the patient groups for each of baseline ARBs. The effects were similar among the groups. $\left.0.81 \pm 0.24 \mathrm{mg} \mathrm{dl}^{-1}, P<0.001\right)$ were evident during the observation period. Estimated glomerular filtration rate (eGFR) was calculated in 96 patients according to the Japanese Society of Nephrology Chronic Kidney Disease Practice Guide, and it was shown to decrease significantly from $70.9 \pm 19.3$ to $66.7 \pm 17.5 \mathrm{ml} \mathrm{min}^{-1} 1.73 \mathrm{~m}^{-2}$ $(P<0.001)$. Of these 96 patients, 77 patients with an eGFR $\geqslant 50 \mathrm{ml}$ $\mathrm{min}^{-1} 1.73 \mathrm{~m}^{-2}$ showed a significant decrease $(76.9 \pm 12.8$ to $71.7 \pm 12.2, P<0.001)$. In the remaining 19 patients with an eGFR $<50 \mathrm{ml} \mathrm{min}^{-1} 1.73 \mathrm{~m}^{-2}$, the eGFR value did not change significantly ( $46.7 \pm 8.6$ to $46.4 \pm 10.7)$. Serum chloride and potassium levels decreased significantly (104 \pm 3 to $103 \pm 3 \mathrm{mEq}^{-1}, P<0.001,4.2 \pm 0.4$ to $4.1 \pm 0.4 \mathrm{mEq}^{-1}, P<0.01$, respectively).

The EQ-5D index values analyzed in 95 patients increased significantly during the study from $1.00(0.71-1.00)$ to $1.00(0.76-1.00)$ $(P<0.01)$. Of these 95 patients, 20 patients with an EQ-5D $<0.7$ showed a significant increase from $0.65(0.59-0.69)$ to $0.67(0.62-$ 0.76) $(P<0.05)$. The score did not change significantly in the remaining 75 patients with an EQ-5D $\geqslant 0.7(1.00(0.77-1.00)$ to 1.00 $(1.00-1.00))$. The VAS analyzed in 96 patients increased significantly from $70.0(68.8-80.0)$ to $80.0(70.0-90.0)(P<0.01)$. Of these 96 patients, 50 patients with a VAS $<70$ showed a significant increase from $70.0(56.3-70.0)$ to $70.0(60.0-80.0),(P<0.001)$. However, in the remaining 46 patients with a VAS $\geqslant 70$, the score did not change significantly (80.0 (80.0-90.0) to $85.0(80.0-90.0))$. The PSQI analyzed in 45 patients decreased significantly from $4.0(2.0-7.0)$ to $3.0(2.0$ 5.0) $(P<0.05)$. Of these 45 patients, 13 patients with a PSQI $\geqslant 5.5$ showed a significant decrease (8.0 (7.0-9.0) to 7.0 (5.0-7.0), $P<0.05)$, whereas the score did not change significantly in the remaining 32 patients with a PSQI $<5.5(3.0(1.0-4.0)$ to $2.5(1.0-4.0)$ ) (Table 3). Finally, the HSS analyzed in 93 patients decreased significantly $(4.0$ $(1.0-9.0)$ to $2.0(1.0-8.0), P<0.05)$ (Figure 5a). In these 93 patients, the change in HSS (the baseline value minus the 3 -month value) correlated with systolic blood pressure $(R=0.241, \quad P=0.0195)$ (Figure 5b).

\section{DISCUSSION}

In this study of hypertensive patients, the replacement of an ARB with a combination pill containing losartan and HCTZ achieved a mean reduction in systolic blood pressure of $21 \mathrm{~mm} \mathrm{Hg}$ and in diastolic blood pressure of $9 \mathrm{~mm} \mathrm{Hg}$. In addition, all the QOL scores we

Table 3 Changes in quality of life (QOL) during the 3-month observation period

\begin{tabular}{|c|c|c|c|c|}
\hline & $\mathrm{n}$ & Baseline & 3 months & Value \\
\hline \multicolumn{5}{|c|}{ EuroQol 5 dimensions (EQ 5D) } \\
\hline & 95 & $1.00(0.71-1.00)$ & $1.00(0.76-1.00)$ & $P<0.01$ \\
\hline$<7$ & 20 & $0.65(0.59-0.69)$ & $0.67(0.62-0.76)$ & $P<0.05$ \\
\hline$\geqslant 7$ & 75 & $1.00(0.77-1.00)$ & $1.00(1.00-1.00)$ & NS \\
\hline \multicolumn{5}{|c|}{ Visual analog scale (VAS) } \\
\hline & 96 & $70.0(68.8-80.0)$ & $80.0(70.0-90.0)$ & $P<0.01$ \\
\hline$<70$ & 50 & $70.0(56.3-70.0)$ & $70.0(60.0-80.0)$ & $P<0.001$ \\
\hline$\geqslant 70$ & 46 & $80.0(80.0-90.0)$ & $85.0(80.0-90.0)$ & NS \\
\hline \multicolumn{5}{|c|}{ Pittsburgh sleep quality index (PSQI) } \\
\hline & 45 & $4.0(2.0-7.0)$ & $3.0(2.0-5.0)$ & $P<0.05$ \\
\hline$<5.5$ & 13 & $3.0(1.0-4.0)$ & $2.5(1.0-4.0)$ & NS \\
\hline$\geqslant 5.5$ & 32 & $8.0(7.0-9.0)$ & $7.0(5.0-7.0)$ & $P<0.05$ \\
\hline
\end{tabular}


a

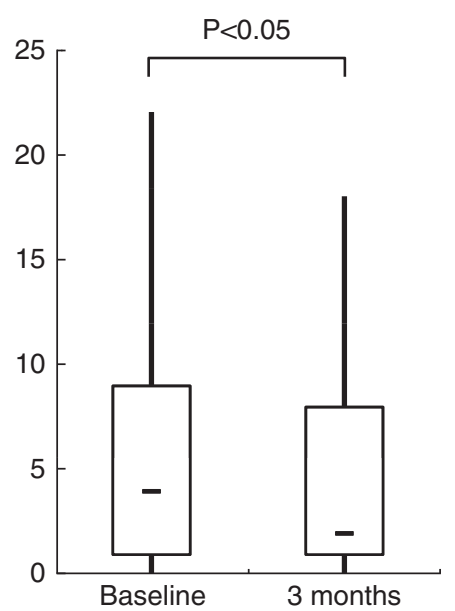

b

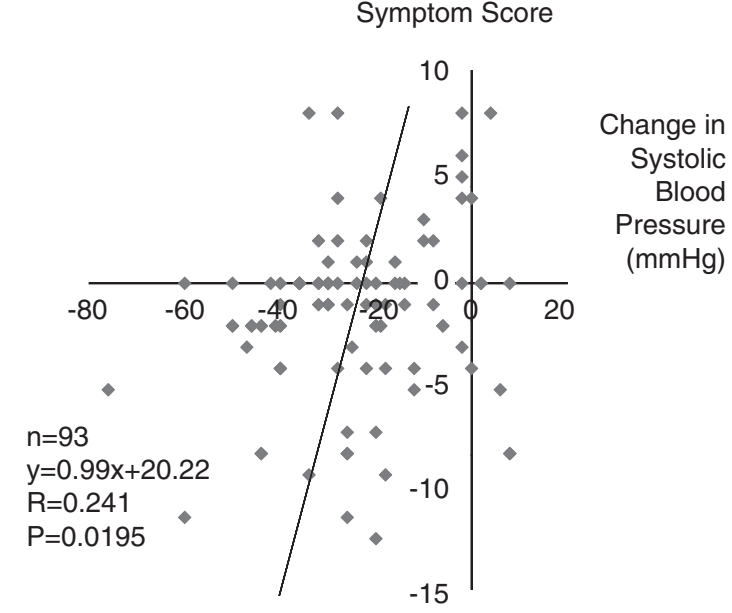

C $\square 0$ Month $\square 3$ Months

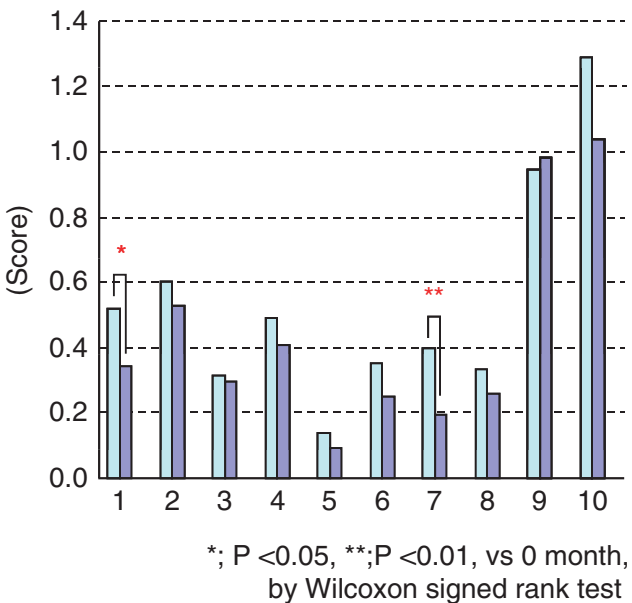

Figure 5 (a) Change in HSS after 3 months of treatment with the losartan $(50 \mathrm{mg}) / \mathrm{HCTZ}(12.5 \mathrm{mg})$ combination pill ( $n=93)$. Overall, HSS decreased significantly (Wilcoxon rank-sum test). The solid line represents the median value; the box, the interquartile range; and the error bar, the $95 \%$ confidence interval. (b) Graph showing the positive correlation between the change in HSS and systolic blood pressure during the 3-month observation period following the replacement of ARBs with the losartan $(50 \mathrm{mg}) / \mathrm{HCTZ}(12.5 \mathrm{mg})$ combination pill. (c) Self-assessment survey completed by patients with hypertension shows detailed examples of the effects of an improved hypertension symptom score. 1: headache or heaviness of head, 2: vertigo or tinnitus, 3: palpitation, 4: shortness of breath, 5: chest pain, 6: dizziness, 7: edema, 8: loss of concentration, 9: polyuria and 10: neck or shoulder stiffness.

measured in the study (that is EQ-5D, VAS, HSS and PSQI) improved after treatment with the losartan/HCTZ combination pill.

Patients seen in primary care settings often present with unspecific symptoms irrespective of the underlying medical problem. Many of these symptoms are non-specific. Patients with hypertension frequently report symptoms that are also reported by normotensive patients. ${ }^{14}$ Hypertension is usually described as asymptomatic in the absence of significant target organ damage and concomitant disease, although cognitive changes, mood alterations and general symptoms, such as dizziness and headache, have been described. ${ }^{15-19}$ Some symptoms are unique to the effects of antihypertensive drugs, whereas others overlap with symptoms described as or attributed to the hypertensive disease itself or are inseparable from those observed throughout the primary care population. ${ }^{14}$

The ultimate goal of antihypertensive treatment is the reduction of cardiovascular mortality and morbidity. To achieve this goal, treat- ment compliance and medication adherence need to be maintained. If patients taking antihypertensive drugs do not feel a reduction in symptoms, it is unlikely that they will comply or adhere to the treatment. Symptoms, whether disease- or treatment-induced, may impair the health-related QOL of patients. QOL refers to the physical, emotional and social impact of a disease and its treatments ${ }^{20,21}$ and is distinct from the physiological measures of disease. ${ }^{20-23}$ Estimation of QOL may assess the impact of a disease and its treatment from a patient's perspective to a greater extent than it assesses conventional clinical symptoms. To estimate the patients' QOL, several scoring systems in the form of questionnaires on various health-related factors have been developed and validated. The EQ-5D is commonly used to measure health-related QOL and has been shown to be responsive, internally consistent and reliable in the normal population and other patient groups. ${ }^{910}$ The VAS is also used to measure health-related QOL. Although it is not as sensitive as other measures, the VAS does 
have considerable merit because of its ease of application, which makes the collection of panel data feasible. ${ }^{11}$ To date, there have been no reports that have specifically evaluated EQ-5D or VAS in the treatment of hypertension. However, another method for evaluating QOL, the 36-item Short Form questionnaire (SF-36), has been used in hypertensive patient populations. Because all these QOL scores represent health-related evaluations, we used our original QOL score from the HSS questionnaire in the present study. This questionnaire focuses on comparatively specific hypertension-related symptoms, calculated as the sum of five graded scores of 10 symptoms. We showed that the HSS score, as well as the EQ-5D and VAS scores, decreased after exchanging ARBs for the combination pill. In addition, the change in HSS score correlated significantly with the decrease in systolic blood pressure. Taken together, these results indicate that lowering blood pressure may improve QOL.

We also evaluated sleep quality with the PSQI during the course of treatment with the combination pill. This measurement showed that blood pressure lowering was associated with improved sleep quality, as shown by a decrease in PSQI. Sleep quality is one of the most important factors contributing to QOL. It has been reported that the prevalence of hypertension in subjects who are 'poor sleepers' is $87.1 \%$ compared with $35.1 \%$ in 'good sleepers. ${ }^{24}$ The increasing interest in the association between sleep disorders and significant comorbidities, including hypertension and glucose metabolism disorders, suggests that studies screening for cardiovascular risk should include an evaluation of sleep quality with questionnaires such as the PSQI. In this regard, our results indicate that the reduction in blood pressure caused by combined losartan /HCTZ treatment may lead to improvements in cardiovascular mortality and morbidity, partially as a consequence of improved sleep quality.

The results of our study also showed that the levels of blood urea nitrogen, uric acid and creatinine increased, whereas eGFR decreased during the 3 months of observation. These results may have been caused by transient decreases in intraglomerular pressure and a subsequent reduction in glomerular filtration, due to the blood pressure-lowering effect of the losartan/HCTZ combination pill. The changes observed in these renal function parameters, however, were within the normal range. In addition, decreases in eGFR were observed only in patients with a normal eGFR $\left(\geqslant 50 \mathrm{ml} \mathrm{min}^{-1} 1.73 \mathrm{~m}^{-2}\right)$, whereas eGFR remained unchanged in patients with a low eGFR $\left(<50 \mathrm{ml} \mathrm{min}^{-1} 1.73 \mathrm{~m}^{-2}\right)$. These findings indicate that there are no safety problems associated with the use of the losartan/HCTZ combination pill. Simultaneous decreases in chloride and potassium levels, possibly caused by the effects of HCTZ, were also within the normal range. In this study, blood examination revealed increases in the plasma uric acid levels after 3 months. This increase might have been induced by the administration of HCTZ.

\section{Potential limitations/clinical implications}

The major limitation of the S-CATS study was an uncontrolled design involving a single-arm treatment in a relatively small number of patients. It is possible that confounding factors affected the present results. Therefore, we need to perform a two-armed randomized study in the future.

Our study included a limited number of patients because we could not obtain the informed consent from all the patients based on the QOL assessment. However, only practitioners of the Saga Medical Association performed this study and similar efforts by practitioners worldwide would be expected to result in improvements in cardio- vascular morbidity and mortality among patients with hypertension. We therefore consider it essential that practitioners who are not specialists in the treatment of hypertension recognize the importance of adequately relieving patients' symptoms, thereby improving QOL and maintaining treatment compliance and medication adherence. On the basis of our results, we envisage that antihypertensive treatment with the losartan/HCTZ combination pill may result in a better longterm prognosis for patients with hypertension, partially as a consequence of improved QOL. In addition, we propose that the evaluation of QOL, including sleep quality, would be useful in the management of hypertension.

\section{CONFLICT OF INTEREST}

The authors declare no conflict of interest.

\section{ACKNOWLEDGEMENTS}

The following physicians in the Saga Medical Association, Japan, have made a significant contribution to this study (S-CATS): Hiroaki Kawano, Minekazu Hashimoto, Kazuo Moroe, Takahiko Imamura, Masanori Shida, Hiroyuki Tanaka, Genichirou Edakuni, Masao Kawahara, Taizou Minami, Shinichi Nakayama, Masanori Nishiyama, Reiko Yosioka, Hideyuki Kamochi, Norio Takeda, Michio Tomonaga, Fumihiko Saito, Mayumi Inoe, Toshifumi Uchida, Sadayoshi Fukuda, Akio Ikeda, Ryouta Kaihara, Katsuhiro Mizoguchi, Katsuya Oshima, Shouhei Sakai, Youichi Setoguchi, Shigeki Sugihara, Syungo Sukehiro, and Ken-ichi Tanaka. We are also thankful for the technical support provided by Sae Katafuchi and Aya Yamada. This study was supported by the Japan Heart Foundation.

1 Turnbull F. Effects of different blood pressure-lowering regimens on major cardiovascular events: results of prospectively-designed overviews of randomised trials. Lancet 2003; 362: 1527-1535.

2 Turnbull F, Neal B, Pfeffer M, Kostis J, Algert C, Woodward M, Chalmers J, Zanchetti A MacMahon S. Blood pressure-dependent and independent effects of agents that inhibit the rennin-angiotensin system. J Hypertens 2007; 25: 951-958.

3 Garfield FB, Caro JJ. Compliance and hypertension. Curr Hypertens Rep 1999; 1: 502-506.

4 Haynes RB, McDonald HP, Garg AX. Helping patients follow prescribed treatment: clinical applications. JAMA 2002; 288: 2880-2883.

5 Triverdi RB, Ayotte B, Edrlman D, Bosworth HB. The association of emortional wellbeing and marital status with treatment adherence among patients with hypertension. J Behav Med 2008; 31: 489-497.

6 DiMatteo MR, Leppper HS, Croghan TW. Depression is a risk factor for noncompliance with medical treatment: meta-analysis of the effects of anxiety and depression on patient adherence. Arch Intern Med 2000; 160: 2101-2107.

7 Brooks R. EuroQol: the current state of play. Health Policy 1996; 37: 53-72.

8 Lamers L, McDonnell J, Stalmeier P, Krabbe PFM, van JB. The Dutch tariff: results and arguments for an effective design for national EQ-5D valuation studies. Health Econ 2006; 15: 1121-1132.

9 Dolan P. Modeling valuations for EuroQol health states. Medical Care 1997; 35: 1095-1108.

10 Brazier J, Deverill M, Green C, Harper R, Booth A. A review of the use of health status measures in economic evaluation. Health Technol Assess 1999; 3: 1-164.

11 Parkin D, Rice N, Lacoby A, Doughty J. Use of a visual analogue scale in a daily patient diary: modelling cross-sectional time-series data on health-related quality of life. Soc Sci Med 2004; 54: 351-360.

12 Buysse DJ, Reynolds III CF, Monk TH, Berman SR, Kupfer DJ. The Pittsburgh Sleep Quality Index: a new instrument for psychiatric practice and research. Psychiatry Res 1989; 28: 193-213.

13 Carpenter JS, Andrykowski A. Psychometric evaluation of the Pittsburgh Sleep Quality Index. J Psychosom Res 1998; 45: 5-13.

14 Kullman S, Svardsudd K. Differences in perceived symptoms/quality of life in untreated hypertensive and normotensive men. Scand J Prim Health Care 1990; 1: 47-53.

15 Battersby C, Hartley K, Fletcher AF, Markowe HJ, Styles W, Sapper H, Bulpitt CJ. Quality of life in treated hypertension: a case-control community based study. J Hum Hypertens 1995; 9: 981-986.

16 Schoenberger JA, Croog SH, Sudilovsky A, Levine S, Baume RM. Self-reported side effects from antihypertensive drugs. A clinical trial. Quality of Life Research Group. Am J Hypertens 1990; 3: 123-132. 
17 Siegrist J, Matschinger H, Motz W. Untreated hypertensives and their quality of life. J Hypertens Suppl 1987; 5: S15-S20.

18 Kjellgren KI, AhIner J, Dahlöf B, Gill H, Hedner T, Säljö R. Perceived symptoms amongst hypertensive patients in routine clinical practice -a population-based study. $J$ Intern Med 1998; 244: 325-332.

19 Muller A, Montoya P, Schandry R, Hartl L. Changes in physical symptoms, blood pressure and quality of life over 30 days. Behav Res Ther 1994; 32 : 593-603.

20 Guyatt GH, Feeny DH, Patrick DL. Measuring health-related quality of life. Ann Intern Med 1993; 118: 622-629.
21 Fitzpatrick R, Fletcher A, Gore S, Jones D, Spiegelhalter D, Cox D. Quality of life measures in health care. I. Applications and issues in assessment. BMJ 1992; 305: 1074-1077.

22 Weinberger M, Kirkman MS, Samsa GP, Cowper PA, Shortliffe EA, Simel DL, Feussner JR. The relationship between glycemic control and health-related quality of life in patients with non-insulin-dependent diabetes mellitus. Med Care 1994; 32: 1173-1181.

23 Beto JA, Bansal VK. Quality of life in treatment of hypertension. A metaanalysis of clinical trials. Am J Hypertens 1992; 5: 125-133.

24 Fiorentini A, Valente R, Perciaccante A, Tubani L. Sleep's quality disorders in patients with hypertension and type 2 diabetes mellitus. Int J Cardiol 2007; 114: e50-e52. 